\title{
Integrating Closed-loop Supply Chains and Spare Parts Management at IBM
}

\author{
Moritz Fleischmann, Jo van Nunen, Ben Gräve
}

\begin{tabular}{|l|l|}
\hline \multicolumn{2}{|l|}{ ERIM REPORT SERIES RESEARCH IN MANAGEMENT } \\
\hline ERIM Report Series reference number & ERS-2002-107-LIS \\
\hline Publication & November 2002 \\
\hline Number of pages & 19 \\
\hline Email address corresponding author & j.nunen@fbk.eur.nl, m.fleischmann@fbk.eur.nl \\
\hline Address & Erasmus Research Institute of Management (ERIM) \\
& Rotterdam School of Management / Faculteit Bedrijfskunde \\
& Erasmus Universiteit Rotterdam \\
& P.O. Box 1738 \\
& 3000 DR Rotterdam, The Netherlands \\
& Phone: +31 104081182 \\
& Fax: $\quad+31104089640$ \\
& Email: info@erim.eur.nl \\
& Internet: $\quad$ www.erim.eur.nl \\
\hline
\end{tabular}

Bibliographic data and classifications of all the ERIM reports are also available on the ERIM website: www.erim.eur.nl 


\title{
ERASMUS RESEARCH INSTITUTE OF MANAGEMENT
}

\author{
REPORT SERIES
}

RESEARCH IN MANAGEMENT

\begin{tabular}{|c|c|c|}
\hline \multicolumn{3}{|c|}{ BIBLIOGRAPHIC DATA AND CLASSIFICATIONS } \\
\hline Abstract & \multicolumn{2}{|c|}{$\begin{array}{l}\text { Ever more companies are recognizing the benefits of closed-loop supply chains that integrate } \\
\text { product returns into business operations. IBM has been among the pioneers seeking to unlock } \\
\text { the value dormant in these resources. We report on a project exploiting product returns as a } \\
\text { source of spare parts. Key decisions include the choice of recovery opportunities to use, the } \\
\text { channel design, and the coordination of alternative supply sources. We developed an analytic } \\
\text { inventory control model and a simulation model to address these issues. Our results show that } \\
\text { procurement cost savings largely outweigh reverse logistics costs and that information } \\
\text { management is key to an efficient solution. Our recommendations provide a basis for } \\
\text { significantly expanding the usage of the novel parts supply source, which allows for cutting } \\
\text { procurement costs. }\end{array}$} \\
\hline \multirow{3}{*}{$\begin{array}{l}\text { Library of Congress } \\
\text { Classification } \\
\text { (LCC) }\end{array}$} & $5001-6182$ & Business \\
\hline & $5201-5982$ & Business Science \\
\hline & HF 5415.135 & Product management, decision making \\
\hline \multirow{4}{*}{$\begin{array}{l}\text { Journal of Economic } \\
\text { Literature } \\
\text { (JEL) }\end{array}$} & M & Business Administration and Business Economics \\
\hline & M 11 & Production Management \\
\hline & R 4 & Transportation Systems \\
\hline & M 11 & Production management \\
\hline \multirow{4}{*}{$\begin{array}{l}\text { European Business Schools } \\
\text { Library Group } \\
\text { (EBSLG) }\end{array}$} & $85 \mathrm{~A}$ & Business General \\
\hline & $260 \mathrm{~K}$ & Logistics \\
\hline & $240 \mathrm{~B}$ & Information Systems Management \\
\hline & $260 \mathrm{~K}$ & Logistiek \\
\hline \multicolumn{3}{|c|}{ Gemeenschappelijke Onderwerpsontsluiting (GOO) } \\
\hline \multirow[t]{4}{*}{ Classification GOO } & 85.00 & Bedrijfskunde, Organisatiekunde: algemeen \\
\hline & 85.34 & Logistiek management \\
\hline & 85.20 & Bestuurlijke informatie, informatieverzorging \\
\hline & 85.35 & Productiemanagement \\
\hline \multirow[t]{3}{*}{ Keywords GOO } & \multicolumn{2}{|c|}{ Bedrijfskunde / Bedrijfseconomie } \\
\hline & \multicolumn{2}{|c|}{ Bedrijfsprocessen, logistiek, management informatiesystemen } \\
\hline & \multicolumn{2}{|c|}{ Logistiek management, toelevering, hergebruik, voorraadbeheer, simulatie } \\
\hline Free keywords & \multicolumn{2}{|c|}{$\begin{array}{l}\text { Supply Chain Management, Reverse Logistics, Service Management, Inventory Management, } \\
\text { Product Recovery }\end{array}$} \\
\hline
\end{tabular}




\title{
Integrating Closed-loop Supply Chains and Spare Parts Management at IBM
}

\author{
by Moritz Fleischmann ${ }^{1}$, Jo van Nunen ${ }^{1}$, Ben Gräve ${ }^{2}$ \\ ${ }^{1}$ Erasmus University Rotterdam, Rotterdam School of Management / Faculteit Bedrijfskunde \\ ${ }^{2}$ IBM, Global Service Logistics
}

\begin{abstract}
Ever more companies are recognizing the benefits of closed-loop supply chains that integrate product returns into business operations. IBM has been among the pioneers seeking to unlock the value dormant in these resources. We report on a project exploiting product returns as a source of spare parts. Key decisions include the choice of recovery opportunities to use, the channel design, and the coordination of alternative supply sources. We developed an analytic inventory control model and a simulation model to address these issues. Our results show that procurement cost savings largely outweigh reverse logistics costs and that information management is key to an efficient solution. Our recommendations provide a basis for significantly expanding the usage of the novel parts supply source, which allows for cutting procurement costs.
\end{abstract}

\section{Introduction}

The traditional view of a supply chain, reflected by numerous textbooks and company web sites, refers to a linear structure, conveying goods from suppliers to manufacturers, wholesalers, retailers, and finally to the consumer. Yet many examples prove this picture to be over simplistic. Today's companies co-operate as complex, general networks rather than one-dimensional 'chains'. In particular, these networks involve several types of goods flows upstream the traditional supply chain, such as returns of overstocks, service parts, and reusable packaging. The management of these product flows has been denoted by reverse logistics.

A class of 'reverse' goods flows that has been gaining particular importance concerns returns of used products at the end of their normal lifecycle. Companies have been discovering used products as a valuable resource. A scale of recovery options, including refurbishing, remanufacturing, and recycling may allow for recapturing significant shares of the original value added and/or material value, thereby opening the route to extended profits [Thierry et al., 1995]. Additional benefits arise through improved corporate citizenship and compliance with environmental regulation. The sum of these factors has given rise to numerous business opportunities for original equipment manufacturers (OEM), specialized remanufacturers and recyclers, and logistics service providers.

At the same time, reverse logistics has been attracting growing interest from academia, as documented by a quickly expanding body of literature [see e.g. Guide and Van Wassenhove, 2002]. The European Union has recognized the impact of reverse logistics by sponsoring a major 5-year research cooperation in this field [REVLOG, 2002]. The study presented in the sequel has made part of this initiative.

Initially, literature has focused very much on understanding the particular logistics requirements of 'upstream' goods flows. In the meantime however, the segregation into 'forward' and 'reverse' flows has made room for a more comprehensive approach, considering an ensemble of interrelated inbound and outbound flows, denoted as 'closed-loop supply chains'. The case of IBM that we present in this paper underlines the necessity of such a holistic perspective. We address the integration of used equipment returns as a supply source into spare parts management. While rotable spares systems have been common practice since long, they typically concern flows on a part level only. In contrast, the exploitation of returned used machines as a source of spares is a fairly novel avenue. While representing an important savings potential, this source also induces significant challenges. In particular, machine returns are uncertain and therefore difficult to coordinate with other parts supply 
sources. The goal of our project was to help IBM master these challenges and establish dismantling of used equipment as a regular source of spare parts.

\section{Reverse Logistics at IBM}

We anchor our project by reviewing IBM's overall reverse logistics activities. The electronics industry has been a key sector in the emergence of closed-loop supply chains for value added recovery. Ever expanding market volumes on the one hand and short product lifecycles on the other hand are resulting in huge amounts of used products being disposed of. In this light, it comes as no surprise that electronic waste has been a prime target of environmental regulation (see e.g. NVMP [2002] or EU[2000]). At the same time, modular product designs and the limited extent of mechanical "wear and tear' sustain the reusability of electronic products and components. Together, both developments result in a significant value recovery potential in this sector.

IBM has been among the pioneers recognizing and exploiting these opportunities. Since long, valuable products and components are being recaptured from streams of post-customer equipment. Today IBM's business activities involve a variety of 'reverse' product flows [IBM, 2000]: Considering the value recovery potential, the most attractive class concerns end-of-lease equipment. To date, leases account for some $35 \%$ of IBM's total hardware sales. In addition, IBM has implemented take-back programs in several countries in North America, Europe, and Asia, which allow business customers to return used products for free or for a small fee. The most traditional class of 'reverse' flows concerns rotable spare parts. Keeping spares in a closed loop by repairing defective replacement parts from the field has been a key element of IBM's service business. Our study addresses the interface between this spare parts system and the return stream of complete machines. Before zooming in on this aspect, let us complete our quick tour d'horizon of IBM's reverse logistics activities.

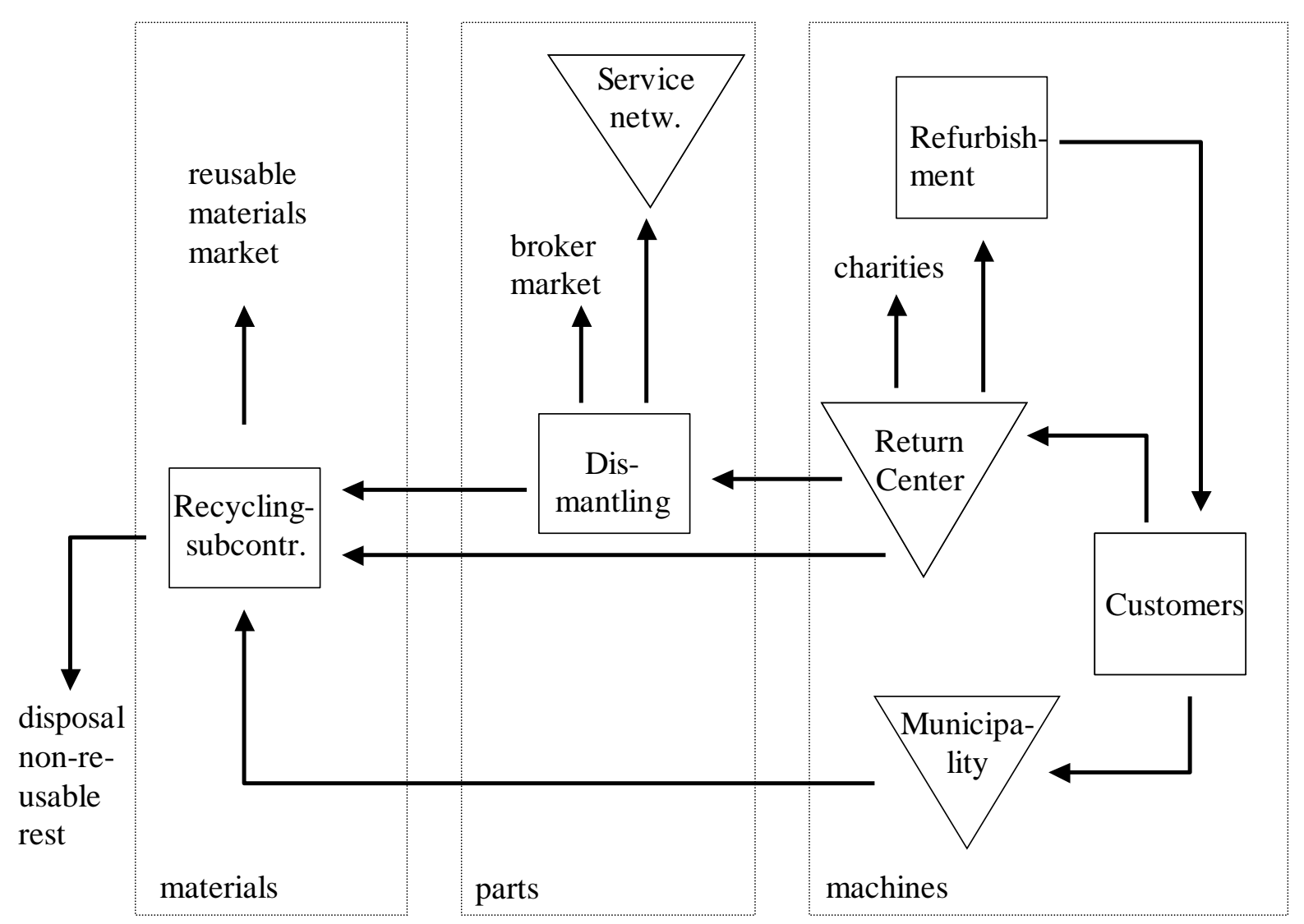

Figure 1: Return dispositioning at IBM includes reuse options on a machine, parts, and material level 
Given its experience, IBM has played an important role in giving shape to industry-wide take-back systems of consumer electronics, in response to environmental regulation. Since individual collection per manufacturer proves inefficient for low value consumer returns, co-operative industry-wide solutions are prevalent for this market sector. In the Netherlands, for example, IBM supports a system organized by the Dutch association of information and communication technology producers, in order to comply with product take-back legislation [NVMP, 2002]. In the USA a different system for consumer returns has recently been implemented. In this case, IBM customers can purchase a recycling service together with any new PC, which allows them later to return the equipment by UPS to a recycling center where it is either prepared for donation to charities or broken down into recyclable materials [IBM, 2000].

Recognizing the growing importance of reverse logistics flows, IBM assigned the responsibility for managing all product returns worldwide to a dedicated business unit in 1998, named Global Asset Recovery Services (GARS). The main goal of this organization is to manage the dispositioning of returned items and thereby to maximize the total value recovered. To this end, GARS operates some 25 facilities all over the globe where returns are collected, inspected, and assigned to an appropriate recovery option. See Figure 1 for an illustration of the different alternatives. Specifically, GARS assesses which equipment may be remarketable, either 'as is' or after a refurbishment process. For this purpose, IBM operates nine refurbishment centers worldwide, each dedicated to a specific product range. Internet auctions, both on IBM's own Web site and on public sites have become an important sales channel for remanufactured equipment. Yet, ever shorter product lifecycles are limiting the reusability of equipment as a whole. Therefore, IBM is considering reuse on a component level as an alternative that may help maximize the revenue generated from the return stream. In particular, dismantling used equipment provides a potential source of spare parts for the service network. It is this option that we address in detail in this paper. In addition, generic components may be sold on the open market. The remainder of the return stream is broken down into recyclable material fractions, which are sold to external recyclers. In this way, landfilling is limited to a few percent of the overall input volume.

\section{The Dismantling Channel}

The option of dismantling used equipment to extract valuable components such as hard-disc assemblies, cards, and boards as spare parts is exploiting the fact that spare parts, in general, have a much longer economic and technical lifecycle than the corresponding original products: service contracts that generate a need for parts extend years beyond the period that a product type is manufactured or that it may be remarketable as a whole. Moreover, individual components of a returned machine may still be well-functioning even if the performance of the product as a whole is unacceptable.

IBM's dismantling operation came into being as an incidental, opportunity-driven activity. When preparing obsolete end-of-lease equipment for scrapping, the engineers preserved a few high-value components, such as expensive cards or hard-discs, which they knew were of value to the service business. These components could then be added to the stock of defective replacement parts awaiting testing and repair within the aforementioned spare parts loop. Since the parts management system did not support this spontaneous supply, some administrative detour had to be taken to make the additional parts 'visible' to the system. To this end, the dismantling parts were kept track of as a distinct stock. Whenever the planning system's MRP engine issued an order for this part type on the repair or the new buy channel, this order was cancelled manually and replaced by an order on the dismantling stock. Figure 2 illustrates these processes.

Gradually, dismantling has been recognized as a potential savings opportunity of a larger scale. The actual disassembly of a given part from a returned machine is fairly inexpensive. The main costs of this supply source concern a thorough test process, which assures that all parts entering the service network meet given quality standards. Yet these costs are significantly lower, in general, than buying a new part. Net savings may amount to up to $80 \%$. Cost differences with the traditional repair channel are less prominent. Yet savings may be realized since parts from dismantling are not necessarily 


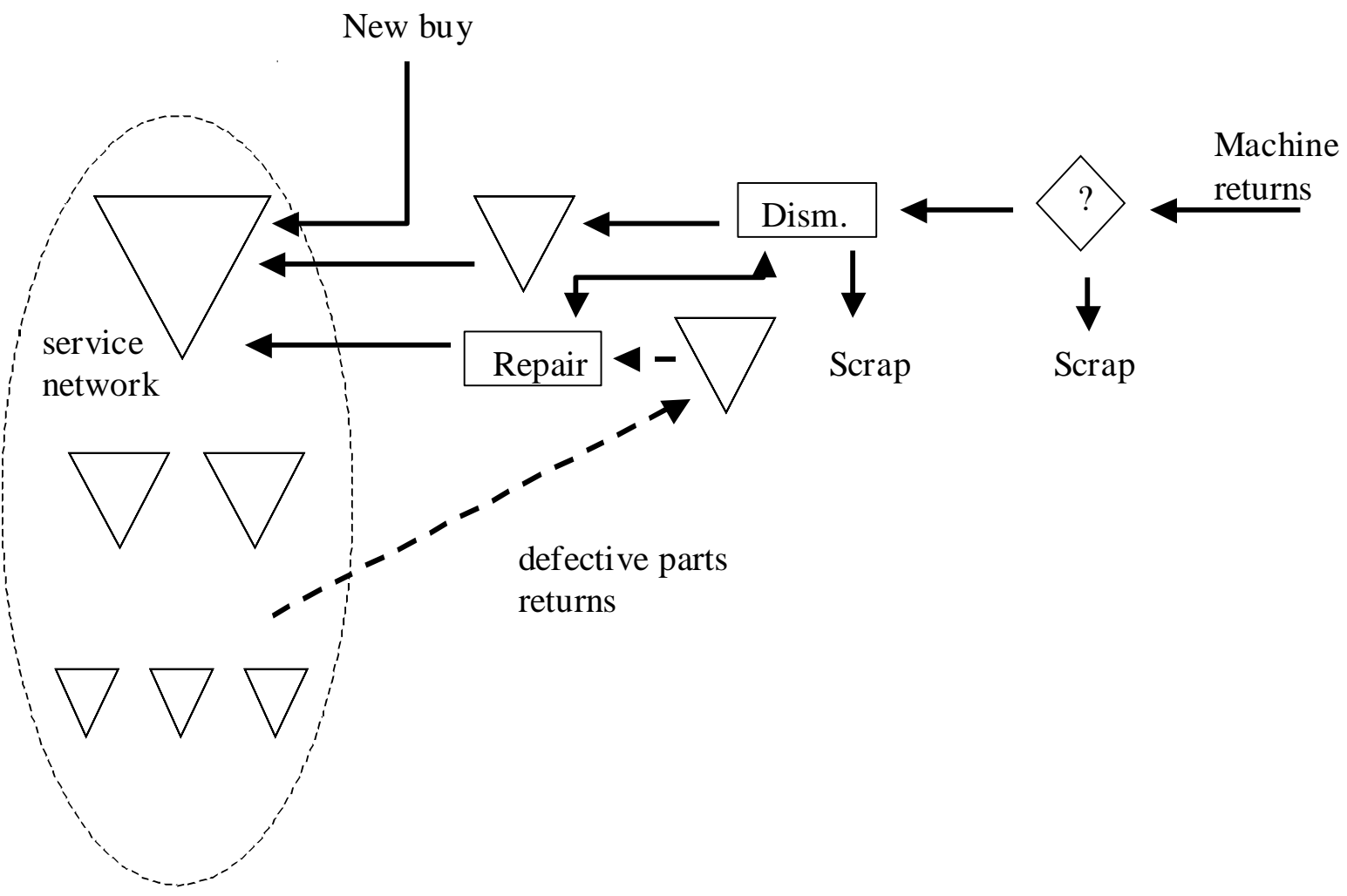

Figure 2: Dismantling returned machines provides an additional source of spare parts

defective, in contrast with returned replacement parts, and therefore provide a higher yield. The attractiveness of the dismantling channel from a cost perspective is counterweighed by its uncertain availability, which complicates a reliable planning.

As volumes were growing, the limitations of the above dismantling policy were becoming apparent. Above all, the missing IT system support hampers a systematic exploitation of the potential of this channel. The significant effort tied to working around system limitations by means of manual intervention, as sketched above, certainly is not a satisfactory solution. Furthermore, one observes a lack of co-ordination and communication between the dismantling operation on the one hand and the parts planning on the other hand. In this way, one might dismantle parts that eventually turn out not to be needed. At the same time, dismantling opportunities may be left untouched since parts needs are not visible to the operations department. On the planning side, expensive new parts may be ordered although they would be available against little cost from dismantling. In the best case, such an order may be cancelled later on. In the worst case, the new part may have to be scrapped, and the investment is lost.

Given these shortcomings, IBM initiated our project in co-operation with its Global Logistics Development Group in Amsterdam. Our goal was to develop a proposal for a systematic integration of dismantling as a regular source into spare parts planning.

\section{Lessons Learned from Literature}

Several streams of research documented in literature provide insight that is helpful for tackling this problem. The most straightforward link points to the theory of repairable inventory systems, which has brought about a rich body of literature since the 1960s [see, e.g. Nahmias, 1981]. This work models networks of stocking points of repairable items, such as spare parts. Given a probabilistic demand process and repair capabilities, appropriate stock levels are determined for each item at each location. Some of the seminal work in this field is due to Sherbrooke [1968]. IBM uses related approaches for determining the stock levels of its repairable spare parts. 
A key assumption of the above models concerns the fact that item returns are generated by failures in the field and therefore trigger an immediate demand for a replacement. This reflects the closed-loop character of rotable spare parts systems. However, the dismantling source described in the previous section clearly violates this assumption. Supply from this channel stems from end-of-lease equipment or environmental take-back that are, in principle, independent of spare parts demand. Therefore, managing IBM's dismantling source goes beyond the scope of traditional repairable inventory theory.

In recent years several authors have addressed stochastic inventory models with item returns that are closer to our setting. One may distinguish single-level models that assume returns to be added directly to the serviceable stock, and bi-level models where returns may be stocked before being recovered. Within the former class, Heyman [1977] analyzes disposal of returns such as to optimize the tradeoff between additional inventory carrying costs and procurement savings. Inderfurth [1997] addresses the disposal decision and the procurement policy simultaneously. In a related paper we have shown that a model with independent demand and returns can, under certain conditions, be reduced to a conventional inventory model, such that methods and results from traditional inventory theory are applicable to the return case (see Fleischmann and Kuik [2002]). We used this model as a basic tool in our analysis of the situation at IBM (see below).

In case recovery may be postponed until returned items are actually needed, the inventory control problem is becoming significantly more complex. In these bi-level models, optimal policies with a simple structure are only obtained in a few special cases (see Inderfurth [1997]). Therefore, several heuristics have been proposed for this setting (see e.g. van der Laan et al. [1999]). Kiesmüller and Minner [2001] and Mahadevan et al. [2002] have recently proposed simple approximation formulas for setting the control parameters, analogous with the usual normal demand approximations for standard inventory models (see e.g. Silver at al. [1998, Chapter 7]).

In addition to these models, which explicitly consider item returns, we found analogies with inventory models from other contexts helpful. In particular, we mention two-supplier models and models with price discounts. Two-supplier models consider the coordination of orders from a cheaper yet slower supplier and from a faster yet more expensive one. Typically, the latter one is used as an emergency source if stock levels drop excessively low, see e.g. Moinzadeh and Nahmias [1988]. Similarly, in our case dismantling, repair, and new buy represent alternative supply sources that need to be coordinated. Yet, the tradeoff is different here, as the cheapest source (dismantling) is also the fastest one.

Several authors have considered the impact of temporary price discounts on inventory control decisions (see e.g. Silver et al. [1993], Moinzadeh [1997]). Discounts, in general, result in higher stock levels. The basic tradeoff is between additional inventory costs and future procurement savings. This setting has much in common with the situation we observed at IBM. Product returns for dismantling can be interpreted as temporary procurement opportunities with a price discount. Yet the correspondence is not perfect, as returned products that are not recovered need to be disposed of and since dismantled parts need to be tested and possibly repaired before being reusable.

\section{Structuring the Problem}

In our project we subdivided the overall goal of establishing a systematic dismantling source into three core issues, namely (i) the design of the dismantling channel, (ii) the selection of which parts to disassemble from a given machine, and (iii) the coordination of dismantling with the other parts supply sources. Below we discuss the issues related to each of these areas.

Considering the first issue, one needs to define per part type the processes that a part from a returned machine needs to undergo before being reusable. The general steps include the actual disassembly, testing, and possibly repair and/or upgrading. In particular, one needs to specify for which part types dismantling is technically feasible at all. In general, dismantling is considered for electronic components such as expensive cards or hard-disc assemblies, which often may be reused 'as is' once they have been successfully tested. In contrast, parts that are subject to mechanical wear, such as keyboards, cannot be recovered in a satisfactory way. In addition, design changes that require older 
parts to be upgraded need to be taken into account. In our project we left the specification of the required processing steps per part type to the expertise of the engineering department.

From a logistics perspective, we need to address the coordination of the individual processing steps, considering the resulting parts flow. In particular, this refers to locating intermediate inventory buffers. To this end, we note that we did not observe any significant economies of scale with respect to the lot size in any of the processing steps and that capacity limitations appeared to be negligible. Therefore, inventories in the dismantling channel primarily play a role as a means for postponing processing expenses until parts are needed. We recall that testing, including potential upgrading, is the major value adding activity within the dismantling channel. In contrast, disassembling parts from a given machine is a relatively quick, low cost operation. In this light, an inventory buffer appears to make sense before the test operation in the first place.

In our analysis we therefore considered two alternative channel designs, which we denote in the sequel as 'pull' versus 'push' dismantling. In the first case one builds up a stock of dismantled parts on which test orders can be placed when needed, in analogy with the traditional repair channel. In the second case dismantled parts are tested as soon as available, after which they are directly added to the serviceable stock. As explained, the first option benefits from postponing the investment for testing, which reduces opportunity costs and the risk of testing parts that are no longer needed. On the other hand, the second option avoids stocking defective parts and reduces the throughput time, which may reduce safety stock. We evaluated the tradeoff between both alternatives in our analysis as explained below.

Concerning the second issue above, one needs to decide which parts to disassemble upon arrival of a returned machine, given the channel design. While for a small-scale operation it was sufficient to rely on the responsible engineers' intuition, growing volumes call for a more systematic analysis of the financial consequences. Since dismantling opportunities do not, in general, occur exactly when the corresponding parts are needed, one needs to make a tradeoff between immediate costs and expected future savings. As disassembly costs are low we consider each part independently. This approach suggests to disassemble those parts, for which the costs for disassembly and testing discounted to the expected moment of use are lower than the cost of disposal plus an alternative future supply discounted to the same moment. When all cost rates are given, this rule comes down to specifying a maximum expected time in stock, or equivalently a maximum stock level beyond which parts are disposed (compare Heyman [1977]).

We add a few remarks concerning the different cost rates. First of all, one needs to be careful with the use of holding cost rates in this context. We were confronted with the argument that dismantling was becoming unattractive if parts were kept in the 'expensive' serviceable stock. The point is that this stock is valued against the weighted average cost over all supply channels. However, a closer look reveals that holding costs based on this valuation do not provide an appropriate basis for the tradeoff of using or not using a given dismantling opportunity. Second, the expected future savings assigned to a current dismantling decision should be measured relative to the supply source that would have been used otherwise. The share of each source in the total supply can be estimated based on lifecycle planning information. Third, internal transfer prices may distort the view on the savings potential of the dismantling source. We observed controversial debates e.g. on how to deal with the remaining book value of a returned lease machine. Our argument is that the decision whether or not to recover a given part should be based exclusively on direct financial implications. Following a supply chain perspective, we did not take department boundaries into account in our analysis. We add as a sideremark that this discussion also underlines the need for a global return dispositioning, that carefully evaluates the potential benefit of alternative recovery options. In the present study we focused on dismantling though, and took return dispositioning as a given.

The third main issue that we addressed in our investigation concerns the coordination of dismantling with other parts supply sources, notably new buy and repair. In particular, this refers to the question of how the dismantling supply should be reflected in the order decisions on those sources. Given the uncertainty around the dismantling channel, planners that we talked to were reluctant to rely on any dismantling input before it was actually available. We refer to this policy as 'reactive' in the sequel. 
Yet others argued for a more proactive approach, seeking to reduce stock levels by adjusting orders for expected future dismantling supply. The key quantity, in this context, concerns the dismantling volume that becomes available during the effective leadtime of other channels, which typically amounts to several weeks.

We observe that the possibilities of a proactive coordination are tightly linked with the information that is available on future dismantling opportunities. In the situation of our project this information was scarce. The exact timing of machine returns appeared hard to forecast. (Note that this is true even in a lease environment since the customer typically has many options for influencing the actual return date, e.g. by extending the contract or by purchasing the machine.) Moreover, it was not clear beforehand whether a given machine would be available for dismantling and which parts exactly it contained. Given these uncertainties, we have focused on assessing the potential benefit of more reliable return forecasting information. To this end, we have analyzed alternative reactive and proactive coordination strategies, supposing that the corresponding information was made available.

\section{Analytic Model and Simulation}

Our solution approach for the above logistics issues was twofold. On the one hand, we addressed a basic inventory control model with product returns, which we could solve analytically. On the other hand, we built a simulation model that captures more details of the problem. In both cases, we considered the service network as a single aggregate stock point. The issue of how to allocate inventory to the different network locations goes beyond the scope of our project.

In essence, integrating dismantling into IBM's parts planning concerns managing an exogenous inbound product flow. The most basic setting of this problem is reflected by a single stock point, which faces stochastic demand and stochastic returns. In our project this corresponds with the case that all dismantling opportunities are used, disassembled parts are tested immediately upon arrival, and there is only one alternative supply source, namely new buy. Mathematically this situation comes down to a standard single item inventory model where demand may be positive or negative. We were able to prove that in this situation a conventional reorder-point order-up-to $(s, S)$ order policy minimizes long-run average costs, if demand and returns are independent, recovery of returns is faster than external supply, and any unmet demand is backordered [Fleischmann and Kuik, 2002]. While the two first conditions hold in our case, the third one does not. In case of a stockout situation IBM issues an emergency supply, which mathematically speaking corresponds with a lost sales model. Yet for sake of simplicity we used the backorder model as a proxy in our analysis. Specifically, since fixed order costs played a subordinate role in our case we used it in the special form of an $(S-1, S)$ base stock model. That means, whenever the inventory position, comprising stock on-hand plus on-order minus backorders, drops below a certain target level $S$ at a review epoch, an external order is placed such as to return to level $S$. In the appendix we give a formal definition of this model.

Results from queueing theory allow us to compute the stationary probability distribution of the inventory position. Specifically, the inventory position at a review epoch is distributed as $S$ plus a random walk on the nonnegative integers. Moreover, as in standard inventory models with backlogging we have that the net stock is distributed as the inventory position minus demand during a leadtime plus review period, which are stochastically independent. This allows us to calculate the long-run average costs for our model as a function of the target base stock level $S$ and thus to compare different strategies for setting this target.

While this basic model captures much of the essence of IBM's dismantling source it certainly is a simplification of the real system. In particular, the following aspects are not included explicitly: the situation at IBM involves two important supply sources in addition to dismantling rather than a single one, namely new buy and repair; disassembled parts may possibly be stocked before being tested; both the dismantling channel and the repair channel have an imperfect yield; demand in a stockout situation is expedited rather than backlogged. Including all of these aspects in an analytic model is prohibitive. We therefore developed a simulation model in order to test our findings in a more detailed picture. 


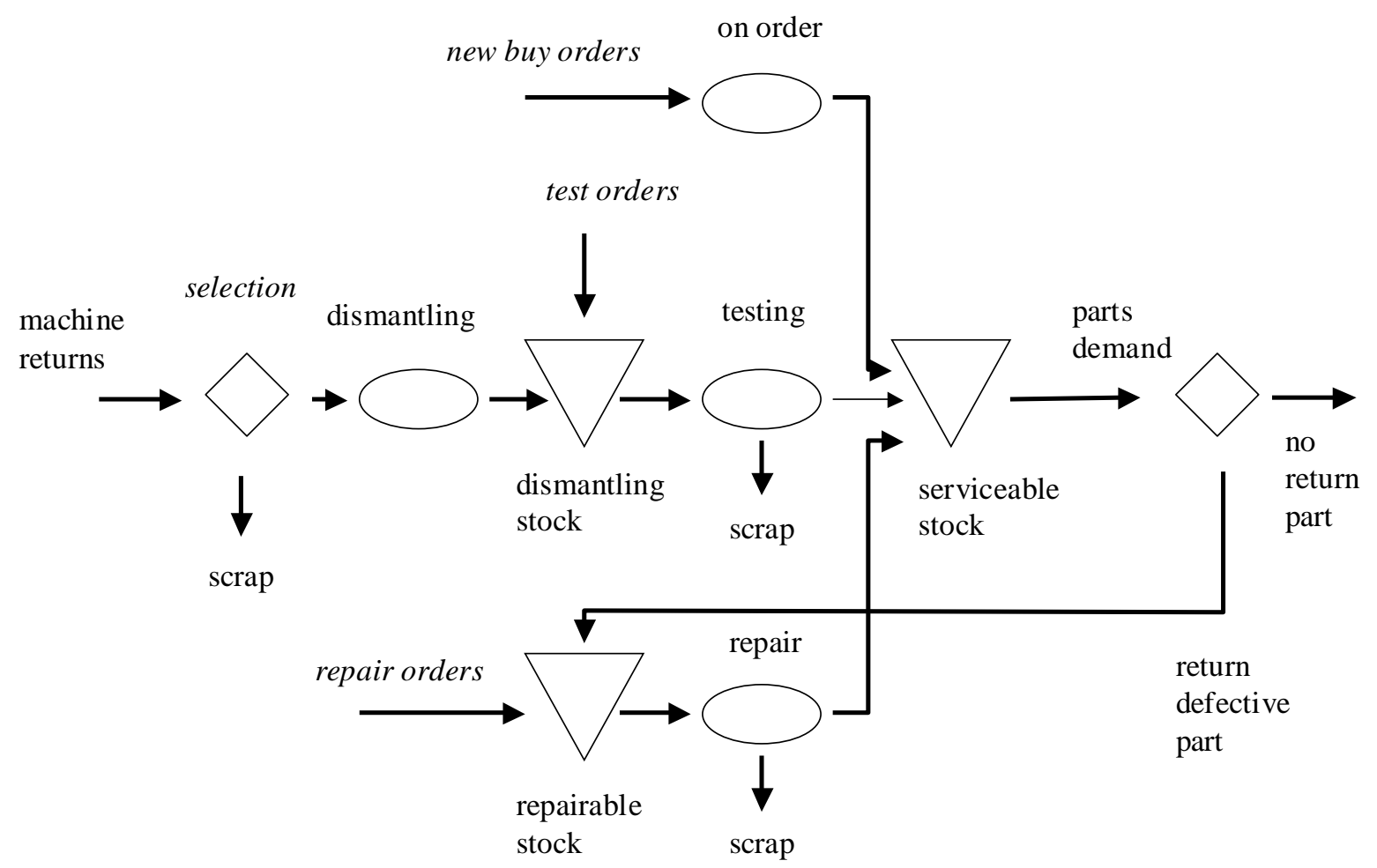

Figure 3: Our simulation model reflects the interaction between three alternative parts sources

Figure 3 summarizes the structure of our simulation model. Specifically, we included the following elements:

- machine return process:

used machines containing the specified part arrive at random moments in small batches of varying size; given the lack of reliable data we opt for a stationary model; rather than modeling the product lifecycle explicitly, we evaluated the model for different parameter settings that reflect different stages in the lifecycle;

- dismantling selection:

depending on actual stock levels and expected future demand, the part is either dismantled or scrapped with the remainder of the machine;

- dismantling process:

as discussed above, economies of scale are small at this stage; moreover capacity restrictions are loose due to the small arrival batches; therefore we assume a fixed processing time and a constant cost per unit;

- dismantling stock:

in line with the above discussion, dismantled parts may possibly be stocked before testing;

- test/upgrade process:

we assume again a fixed processing time and constant unit costs; a dismantled part passes the test process with a fixed probability and is scrapped otherwise;

- serviceable stock:

as discussed above, we model the serviceable stock in the service network as a single inventory level;

- new buy orders:

orders are generated periodically and arrive after a fixed leadtime; unit costs are constant;

- defective parts return process: 
each demand triggers the return of a defective part with a constant probability;

- repairable stock:

defectives are stocked until a repair order is placed;

- repair process:

in analogy with the test process we assume a fixed repair yield, a fixed processing time, and constant unit costs;

- demand process:

in analogy with the return process, parts demand occurs at random moments at a stationary rate; demand during a stockout situation is expedited, thereby causing a penalty cost;

The model encompasses three sets of decisions that reflect our general discussion above, namely choosing whether or not to make use of a given dismantling opportunity, controlling test orders on dismantled parts, and adjusting the order strategies for other sources, i.e. repair and new buy. For each of them we evaluated the different alternatives motivated above. To this end, we compared average annual costs, consisting of procurement costs (new buy order costs and processing costs for dismantling, testing, and repair), holding costs (serviceable stock, repairable stock, and possibly dismantled stock), and stockout penalty costs.

\section{Findings and Recommendations}

Figures 4 and 5 illustrate the outcomes of the analytic model and the simulation, respectively. While the underlying data in this example does not correspond with any specific IBM part, the results are representative of our findings. See the appendix for the detailed parameter values.

Figure 4 shows the average inventory and backorder costs as a function of the dismantling coverage (in percentage of demand) for three alternative order policies, i.e. for three alternative strategies for setting the base stock target $S$, in terms of our model. The solid line corresponds with using the

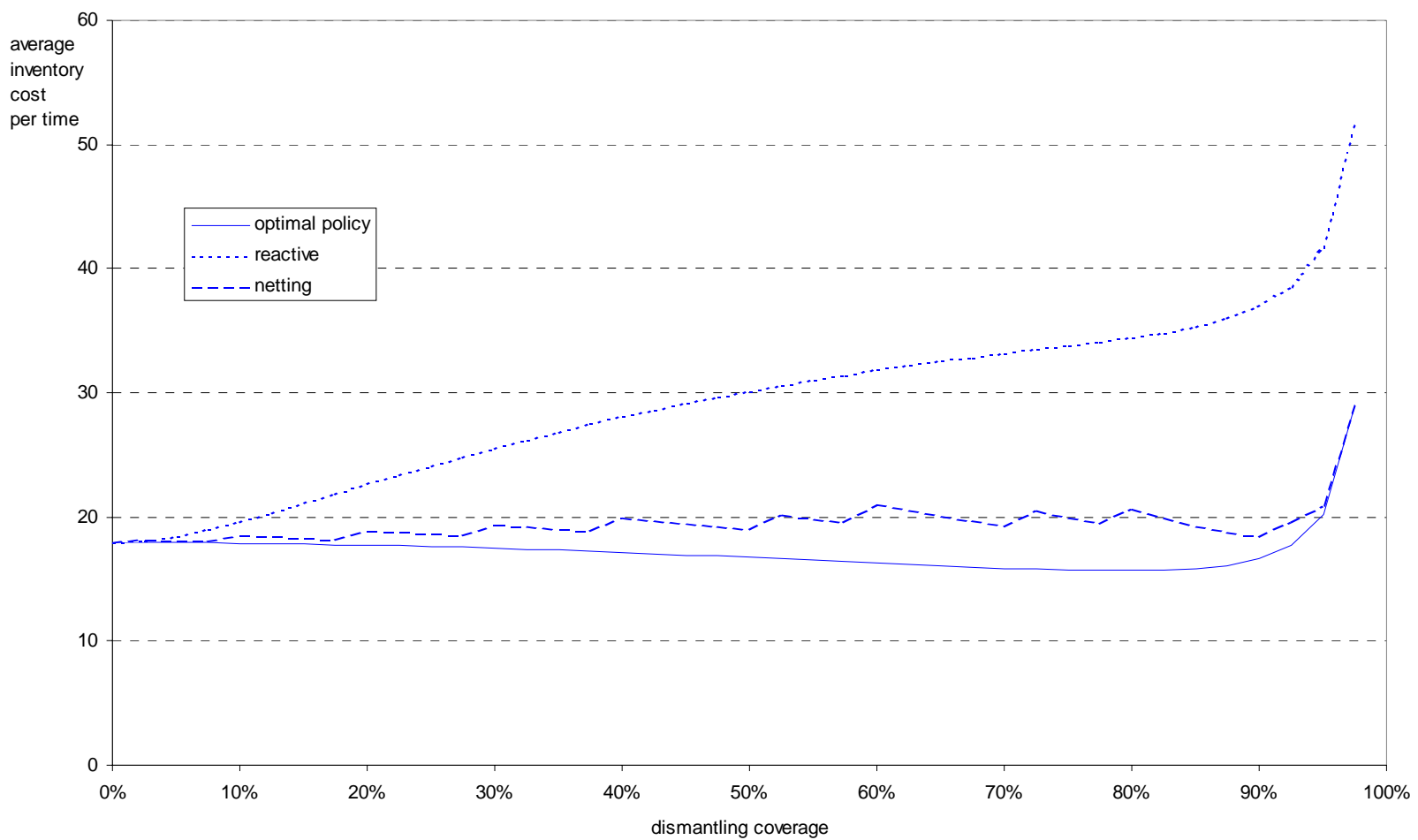

Figure 4: Neglecting future dismantling input entails excessive stock levels whereas a simple netting rule is close to optimal. 
optimal base stock level for controlling new buy orders in each case. The dotted line concerns a reactive policy that does not take the dismantling coverage into account for determining the base stock target. Note that this comes down to applying the optimal target for the case without dismantling throughout the entire interval. The dashed line corresponds with a netting policy that reduces the target level of the case without dismantling by the expected dismantling supply during the order lead time plus review period.

Figure 5 compares the costs for several alternative strategies in the simulation model. The two rightmost columns depict total costs without dismantling and with a dismantling coverage of $30 \%$. Procurement costs in case of dismantling are identical across all strategies. The remaining columns break up the inventory related costs in more detail. The leftmost column concerns the case without dismantling and uses optimal base stock targets for controlling new buy and repair orders. The other columns correspond with six alternative strategies for integrating the dismantling source, based on two alternative channel designs and three alternative coordination mechanisms with the original sources. The push policies test each dismantled part immediately, while the pull policies build up inventory of dismantled parts, on which test orders are placed according to a base stock policy. Analogous with the analytic model, the reactive policies use the base stock target levels of the case without dismantling for controlling new buy and repair orders. The netting policies reduces new buy orders by the expected dismantling input during the order lead time plus review period. The optimal policies rely on jointly optimizing the order levels for the different sources, given the dismantling channel design.

The outcomes of our models provide a basis for assessing the different options for integrating the dismantling source into the parts planning. We discuss our observations and recommendations in the order of their cost impact.

First of all, we observe that procurement costs largely outweigh inventory related costs in all cases. This effect is clearly reflected in Figure 5. Therefore, exploitation of dismantling opportunities should be maximized. This result is also reflected in the fact that the critical storage time computed in the dismantling selection tradeoff is hardly ever reached. In the example in Figure 5 we limited the demand horizon for dismantling to one year, yet the actual storage time never exceeded 3 months.

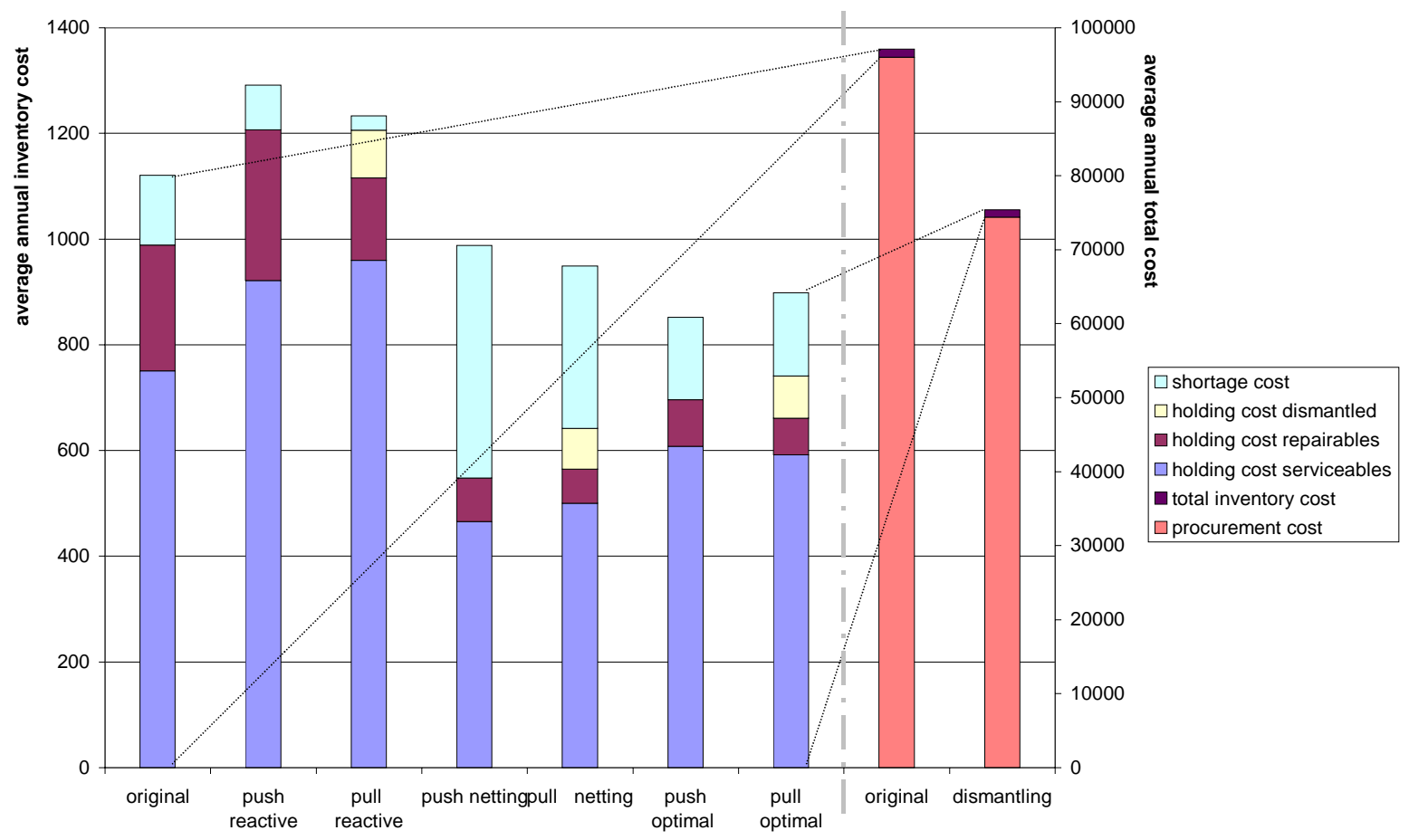

Figure 5: The simulation output shows the cost break-up of the alternative strategies for integrating the dismantling source. 
These observations hold throughout the scenarios that we analyzed. Naturally, the overall cost reduction achieved by dismantling very much depends on the differences in unit processing costs. Yet the dominance of procurement costs over inventory related costs was literally unaffected by this factor. We found this relationship changed only in case of very high dismantling supply (beyond $90 \%$ of demand). We note that Teunter and Vlachos [2002] have recently presented similar results.

Based on these observations we recommended to make use of any dismantling opportunity as long as there is any uncovered demand. Holding costs are hardly relevant to this decision. Scrapping reusable parts only makes sense at the end of a part's lifecycle when parts risk not being used at all. In particular, dismantling should be terminated once the available stock is sufficient to cover the remainder of the service horizon. Similarly, engineering changes may be a factor of importance in this context.

Second, return forecasting information may allow for a significant stock reduction through improved coordination of alternative supply sources. A reactive approach, which only takes dismantled parts into account once they are available, consistently yields the highest costs in all of the cases we analyzed. The magnitude of the cost advantage of a more proactive coordination depends on several factors but can easily approach $50 \%$. This ratio tends to increase with the lead times of the original channels, the dismantling coverage, and the demand volume. As expected, a simple netting approach of reducing orders on more expensive sources by the expected dismantling supply during their leadtime is overly optimistic, as it treats returns as a perfectly reliable source. Uncertainty in the return process causes the servicelevel to drop. Yet from a cost perspective netting turned out to be surprisingly close to the optimal policy in many cases and consistently outperformed reactive strategies. Optimal coordination is achieved by reducing the original order sizes by somewhat less than the expected dismantling supply. A certain safety margin should be employed to buffer against return uncertainty. The size of this correction increases with the variability of the machine return process.

These results clearly highlight the benefits of reliable forecasting information on the returns of used equipment. Potential starting points for building up this type of information include historical data, installed base data, and product lifecycle data. Our models provide the basis for a cost benefit analysis of a corresponding information system. In addition to statistical forecasting methods, advanced information technology may allow for actually monitoring or even controlling product returns. We return to this issue below.

Third, the choice between a push and a pull strategy for dismantling had a fairly limited cost impact in all of the cases that we analyzed. This is supported by the fact that the average time in the dismantling stock in case of pull is very short. In general, postponing the testing of dismantled parts tended to yield a slight cost advantage in the case of reactive coordination and partly in the case of netting. On the other hand, a push channel slightly outperformed a pull channel for the optimal policy. Yet in all cases the effect of the channel design is clearly subordinate to the impact of the coordination strategy.

Given the very limited postponement even in case of a pull design, we recommended testing all dismantled parts immediately. By eliminating the intermediate stock location, this policy yields additional benefits in terms of administration and handling. Moreover, managing such a push policy is easier than optimizing the exact timing of the test operation for each part. In analogy with our remark concerning the dismantling selection, a slight modification of the dismantling policy may be beneficial at the end of a part's lifecycle. Once it is no longer sure whether a given part will eventually be needed, it may make sense to put aside a number of untested parts as an additional backup.

\section{Conclusions}

We presented our findings to IBM's internal service logistics consulting group, that has been involved in the design of an IBM-wide parts planning system and in managing the interface with the Asset Recovery business unit. Feedback was very positive. Our partners appreciated the systematic analysis of the underlying logistics processes, which they felt helped them identify and understand the different design alternatives. They stated that our results provided a good basis for integrating the dismantling 
source into spare parts management in a well-structured way. In addition, our analysis of the alternative dismantling channel designs has triggered a yet ongoing discussion on similar issues in the repair channel. Our project partners also believed that our clear statements concerning the dominance of procurement costs over inventory related costs, would help reduce skepticism within the organization as to the benefits of dismantling despite the burden of its inherent uncertainty. Moreover, the benefits of coordination, which our study clearly revealed, provided them with another strong argument for an overall integrated parts planning system.

In the meantime, the dismantling operation has been moved under the responsibility of the Asset Recovery organization. In line with our recommendation, parts for which a test process is available are dismantled, based on the forecasted uncovered demand within a certain time horizon. Moreover, all dismantled parts are tested before being stocked. Moving from the original case-by-case decision to this systematic rule has allowed for increasing the overall dismantling volume to millions of parts. In particular, the dismantling portfolio has been extended from a few high value parts to high volume commodity parts. In this way, average parts costs have been reduced and the value extracted from used equipment has been growing. Overall benefits amount to several million US\$ annually. In view of these results dismantling will be incorporated as a regular source in the new parts management system, which is currently being prepared.

What can managers learn from our experience? We believe that the following lessons may be useful. First, we would like to draw attention to the option of exploiting product returns as a source of spare parts. To date, many reverse logistics systems focus on recovering products as a whole. Yet, ever decreasing product lifecycles are limiting the market opportunities for this option. In contrast, service business covers much longer horizons and thereby provides extra opportunities for extracting value from product return streams. This is the more true since regular sourcing options for spare parts are becoming limited at later stages of the service horizon. Second, return dispositioning needs to be carefully managed in order to maximize the value recovered. In particular, the previous argument underlines that the value of a product's components may exceed its value as a product. Instead of simplistic priority rules, dispositioning therefore requires a conscious analysis of the financial results of all available reuse options. Third, information management is key to realizing an efficient closedloop supply chain. Many companies today accept product returns as a given, to which they only react once they have it in their hands. In our analysis we have illustrated that a more proactive perspective that recognizes returns as valuable resources yields tangible benefits. To this end, companies must understand their return flows and be able to anticipate on them. While developing great sophistication in demand forecasting, few companies to date are collecting any systematic data on product returns. Yet return forecasting is but a first step. Even greater opportunities come into reach as companies use information for actively managing their returns rather than accepting them as a given. Advances in information technology, including data logging, radio frequency identification, and remote sensing provide ever more powerful means for pursuing this road.

\section{References}

EU. 2000. "Proposal for a directive of the European Parliament and of the Council on waste electrical and electronic equipment", $\operatorname{COM}(2000) 347$ retrieved on November 4, 2002 from http://europa.eu.int/eur-lex/en/com/pdf/2000/en_500PC0347_02.pdf

Fleischmann, M.; Kuik, R. 2002, "On Optimal Inventory Control with Stochastic Item Returns", European Journal of Operational Research, forthcoming.

Guide, Jr., V.D.R.; Van Wassenhove, L.N. 2002, Business Perspectives on Closed-loop Supply Chains, Carnegie Bosch Foundation, Pittsburgh, Pennsylvania, forthcoming.

Heyman, D.P. 1977, “Optimal Disposal Policies for a Single-item Inventory System with Returns”, Naval Research Logistics Quarterly, Vol.24, p.385-405. 
IBM. 2000. "Environment \& Well-being”, Progress Report retrieved on August 6, 2002 from http://www.ibm.com/ibm/environment

Inderfurth, K. 1997, "Simple Optimal Replenishment and Disposal Policies for a Product Recovery System with Leadtimes", OR Spektrum, Vol.19, No.2, p.111-122.

Kiesmüller, G.P.; Minner, S. 2001, "Simple Expressions for Finding Recovery System Inventory Control Parameters", Working Paper, University of Magdeburg, Germany.

Mahadevan, B.; Pyke, D.F.; Fleischmann, M. 2002, "Periodic Review, Push Inventory Policies for Remanufacturing", Working Paper, Erasmus University Rotterdam, The Netherlands.

Moinzadeh, K. 1997, "Replenishment and Stocking Policies for Inventory Systems with Random Deal Offerings", Management Science, Vol.43, No.3, p.334-342.

Moinzadeh, K.; Nahmias, S. 1988, "A Continuous Review Model for an Inventory System with Two Supply Modes”, Management Science, Vol.34, No.6, p.761-773.

Nahmias, S. 1981, "Managing Repairable Item Inventory Systems: A Review", in Multi-Level Production/Inventory Control Systems: Theory and Practice, ed. L. B. Schwarz, North-Holland, Amsterdam, The Netherlands, p. 253-277.

NVMP 2002, "Regulation for Disposal of Electrical Goods in The Netherlands", retrieved on August 6, 2002 from http://www.nvmp.nl/html/10_english/01_fr_english.htm

REVLOG 2002, "The European Research Network on Reverse Logistics", retrieved on August 6, 2002 from http://www.fbk.eur.nl/OZ/REVLOG/

Sherbrooke, C. C. 1968, "METRIC - A Multi-Echelon Technique for Recoverable Item Control", Operations Research, Vol.16, No.1, p.103-121.

Silver, E. A.; Pyke, D. F.; Peterson, R. 1998, Inventory Management and Production Planning and Scheduling (3 ed.), John Wiley \& Sons, New York.

Silver, E.A.; Robb, D.J.; Rahnama, M.R. 1993 "Random Opportunities for Reduced Cost Replenishments", IIE Transactions, Vol. 25, No.2, p.111-120.

Thierry, M.C.; Salomon, M.; Van Nunen, J.; Van Wassenhove, L. 1995 "Strategic issues in product recovery management”, California Management Review, Vol. 37, No.2, p.114-135.

van der Laan, E.; Salomon, M.; Dekker, R.; Van Wassenhove, L. 1999 "Inventory control in hybrid systems with remanufacturing", Management Science, Vol. 45, No.5, p.733-747.

Teunter, R.H.; Vlachos, D. 2002 "On the necessity of a disposal option for returned items that can be remanufactured”, International Journal of Production Economics, Vol. 75, No.3, p.257-266.

\section{Appendix}

- Definition of the $(S-1, S)$ inventory model with product returns

Notation:

- $\quad D_{n} \quad$ net demand (i.e. demand - returns) in period $n$

- $\quad I_{n} \quad$ inventory position at the beginning of period $n$ after ordering

- $\quad Y_{n} \quad$ net stock at the end of period $n$

- $\quad S \quad$ order-up-to level

- $\quad c_{h} \quad$ holding cost per item per time 
- $\quad c_{b} \quad$ backorder cost per item per time

- $\tau \quad$ order lead time

We assume $\left(D_{n}\right)$ to be a sequence of independent, identically distributed random variables with $\mathrm{E}\left[D_{n}\right]>0$. Then $\left(I_{n}\right)$ forms a Markov chain with the following transition rule

$$
I_{n+1}=\max \left(S, I_{n}-D_{n}\right) \text {. }
$$

Moreover, we have the relation

$$
Y_{n}=I_{n-\tau}-\sum_{i=0}^{\tau} D_{n-i}
$$

where the two operands on the right hand side are independent. This allows us to evaluate the long run average system costs, defined as

$$
\lim _{\mathrm{n} \rightarrow \infty} \mathrm{E}\left[c_{h} \max \left(0, Y_{n}\right)+c_{b} \max \left(0,-Y_{n}\right)\right]
$$

- $\quad$ Parameter settings Figure 4

- $D_{n} \quad=\quad D_{n}^{+}-D_{n}^{-}$

- $D_{n}^{+} \quad \sim \quad \operatorname{Poisson}(10)$

- $D_{n}{ }^{-} \quad \sim \quad \operatorname{Poisson}(\lambda)$, with $\lambda \in[0 ; 9.75]$

- $c_{h}=\$ 1,-/$ item $/$ period

- $c_{b}=\$ 50,-/$ item $/$ period

$-\tau=5$

- Parameter setting Figure 5

- $\quad$ part demand process (unit/month): Poisson(100)

- $\quad$ part return probability: 0.8

- machine return batch arrival (unit/month): Poisson(8.569)

- $\quad$ machine return batch size: Uniform[1;10]

- $\quad$ test yield dismantling: 0.7

- $\quad$ repair yield: 0.5

- $\quad$ lead time new buy: 2 months

- $\quad$ lead time repair: 1.5 months

- lead time dismantling: 0.25 months

- $\quad$ unit order cost new buy: \$100,-

- $\quad$ unit repair cost: $\$ 50$,-

- unit dismantling cost: $\$ 40$,-

- $\quad$ unit stockout cost: \$110,-

- annual holding cost rate: $20 \%$ 


\section{Publications in the Report Series Research ${ }^{*}$ in Management}

ERIM Research Program: "Business Processes, Logistics and Information Systems"

\section{2}

The importance of sociality for understanding knowledge sharing processes in organizational contexts Niels-Ingvar Boer, Peter J. van Baalen \& Kuldeep Kumar ERS-2002-05-LIS

Crew Rostering for the High Speed Train

Ramon M. Lentink, Michiel A. Odijk \& Erwin van Rijn

ERS-2002-07-LIS

Equivalent Results in Minimax Theory

J.B.G. Frenk, G. Kassay \& J. Kolumbán

ERS-2002-08-LIS

An Introduction to Paradigm

Saskia C. van der Made-Potuijt \& Arie de Bruin

ERS-2002-09-LIS

Airline Revenue Management: An Overview of OR Techniques 1982-2001

Kevin Pak \& Nanda Piersma

ERS-2002-12-LIS

Quick Response Practices at the Warehouse of Ankor

R. Dekker, M.B.M. de Koster, H. Van Kalleveen \& K.J. Roodbergen

ERS-2002-19-LIS

Harnessing Intellectual Resources in a Collaborative Context to create value

Sajda Qureshi, Vlatka Hlupic, Gert-Jan de Vreede, Robert O. Briggs \& Jay Nunamaker

ERS-2002-28-LIS

Version Spaces and Generalized Monotone Boolean Functions

Jan C. Bioch \& Toshihide Ibaraki

ERS-2002-34-LIS

Periodic Review, Push Inventory Policies for Remanufacturing

B. Mahadevan, David F. Pyke, Moritz Fleischman

ERS-2002-35-LIS

Modular Decomposition of Boolean Functions

Jan C. Bioch

ERS-2002-37-LIS

Classification Trees for Problems with Monotonicity Constraints

R. Potharst \& A.J. Feelders

ERS-2002-45-LIS

\footnotetext{
A complete overview of the ERIM Report Series Research in Management: http://www.ers.erim.eur.nl

ERIM Research Programs:

LIS Business Processes, Logistics and Information Systems

ORG Organizing for Performance

MKT Marketing

F\&A Finance and Accounting

STR Strategy and Entrepreneurship
} 
Allocation of Railway Rolling Stock for Passenger Trains

Erwin Abbink, Bianca van den Berg, Leo Kroon \& Marc Salomon

ERS-2002-47-LIS

Monotone Decision Trees and Noisy Data

Jan C. Bioch and Viara Popova

ERS-2002-53-LIS

Business Modeling Framework For Personalization In Mobile Business Services: a Case and Sociological Analysis L-F Pau, Jeroen Dits

ERS-2002-56-LIS

Polynomial time algorithms for some multi-level lot-sizing problems with production capacities Stan van Hoesel, H. Edwin Romeijn, Dolores Romero Morales, Albert P.M. Wagelmans ERS-2002-59-LIS

A Note on Ending Inventory Valuation in Multiperiod Production Scheduling

Wilco van den Heuvel, Alfred P.M. Wagelmans

ERS-2002-63-LIS

Determining The Optimal Order Picking Batch Size In Single Aisle Warehouses

Tho Le-Duc and René B.M. de Koster

ERS-2002-64-LIS

Solving Variational Inequalities Defined on A Domain with Infinitely Many Linear Constraints

Shu-Cherng Fang, Soonyi Wu, Ş. Illker Birbil

ERS-2002-70-LIS

Entropic Regularization Approach for Mathematical Programs with Equilibrium Constraints

Ş. Illker Birbil, Shu-Cherng Fang, Jiye Han

ERS-2002-71-LIS

On the Finite Termination of An Entropy Function Based Smoothing Newton Method for Vertical Linear Complementarity Problems

Shu-Cherng Fang, Jiye Han, Zhenghai Huang, Ş. Illker Birbil

ERS-2002-72-LIS

The Role Of Product Quality Information, Market State Information And Transaction Costs In Electronic Auctions Otto Koppius and Eric van Heck

ERS-2002-73-LIS

Shunting of Passenger Train Units in a Railway Station

Richard Freling, Ramon M. Lentink, Leo G. Kroon, Dennis Huisman

ERS-2002-74-LIS

Inventory strategies for systems with fast remanufacturing

Ruud Teunter, Erwin van der Laan, Dimitrios Vlachosz

ERS-2002-77-LIS

A Business Evaluation Of The Next IPv6 Protocol In Fixed And Mobile Communication Services: An Analytical Study And Calculation

L-F Pau

ERS-2002-78-LIS

IPv6 Return on investment (R.O.I) analysis framework at a generic level, and first conclusions

L-F Pau

ERS-2002-79-LIS 
On Borel Probability Measures and Noncooperative Game Theory

J.B.G.Frenk, G.Kassay, V.Protassov

ERS-2002-85-LIS

The Newsboy Problem with Resalable Returns

Julien Mostard, Ruud Teunter

ERS-2002-89-LIS

Integrating Closed-loop Supply Chains and Spare Parts Management at IBM

Moritz Fleischmann, Jo van Nunen, Ben Gräve

ERS-2002-107-LIS

Eliciting Expert Knowledge for Fuzzy Evaluation of Agricultural Production Systems

A. M. G. Cornelissen, J. van den Berg, W. J. Koops, U. Kaymak

ERS-2002-108-LIS

Efficient Circulation of Railway Rolling Stock

Arianna Alfieri, Rutger Groot, Leo Kroon, Lex Schrijver

ERS-2002-110-LIS

Direct Mailing Decisions for a Dutch Fundraiser Jedid-Jah Jonker, Nanda Piersma, Rob Potharst

ERS-2002-111-LIS 